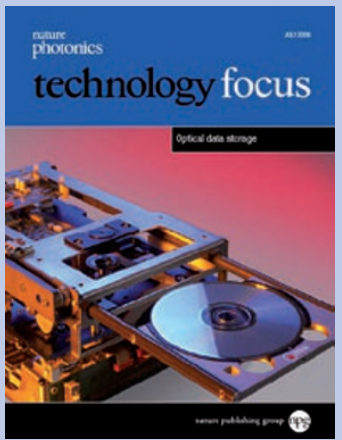

Cover image

A test station from the German company Toptica for Blu-ray disks and drives.

Product Highlights p411

EDITORS: NADYAANSCOMBE, OLIVER GRAYDON

PRODUCTION EDITOR: CHRIS GILLOCH

COPY EDITOR: ANNA DEMMING

ART EDITOR:TOM WILSON

naturephoton@nature.com

\title{
A matter of format
}

RESEARCH HIGHLIGHTS

blue-laser-based DVDs is over, and Blu-ray has triumphed over high-definition DVD (HD-DVD). The big question is what happens next? First the market needs time to readjust, and after this initial period we should see a steady growth in sales of Blu-ray disk systems according to industry analysts (page 410). However, this period of readjustment may take longer than expected. It appears that the format war has had two adverse effects on the industry as a whole, which may delay growth. First, it caused a decrease in prices faster than manufacturers would have liked (page 412). Second, the companies were so busy securing big clients in the entertainment industry that they did not focus on consumer marketing and developing new applications for their products. The time has now come to get down to the normal business of selling systems and developing the market.

In the mean time, the rest of the optical data-storage industry will carry on doing what it has always done well - innovate. Although Blu-ray is enjoying its recently acquired market dominance, other technologies in the lab are fighting it out to offer the next leap in data-storage capacity. Researchers are investigating completely new ways of storing data and three-dimensional storage seems to be the answer, whether in the shape of holographic (page 403) or two-photon technology (page 406). This is an exciting time for optical data storage because holographic technology has been promising great things for many many years, and it looks certain that it will finally become a market reality this year with a product from US company InPhase.

It will be interesting to see if these new technologies get locked into the type of format war that has plagued Blu-ray and HD-DVD. In the meantime, the 25 Gbyte and 50 Gbyte per disk offered by Blu-ray should be more than enough to satisfy most consumer applications for the near future.
402

\section{Dots boost data storage, phase-change revelations, and more}

\section{INDUSTRY PERSPECTIVE 403 Holographic data storage: Coming of age Lisa Dhar, Kevin Curtis and Thomas Fäcke}

406

Two-photon technology: Edwin Walker and Peter M. Rentzepis

\section{BUSINESS NEWS}

410

Blue-laser patent battles, optical-disk test standards, and more

\section{PRODUCT HIGHLIGHTS}

411 Laser-diode developments, dual-layer disk manufacture, and more

\section{INTERVIEW} Interview with David Bunzel A new dimension 